\title{
Furfural Oxidation with Hydrogen Peroxide Over ZSM-5 Based Micro-Mesoporous Aluminosilicates
}

\author{
Nataliya D. Shcherban ${ }^{1} \cdot$ Roman Yu. Barakov $^{1}$ - Sergii A. Sergiienko ${ }^{2} \cdot$ Kari Eränen $^{3}$. Johan Wärnå3 . \\ Dmitry Yu. Murzin ${ }^{3}$
}

Received: 5 November 2021 / Accepted: 11 December 2021 / Published online: 28 December 2021

(c) The Author(s) 2021

\section{Abstract}

Micro-mesoporous aluminosilicates based on ZSM-5 zeolite, obtained by a dual template method, as well as in the presence of a dual-functional template (i.e. a Gemini-type surfactant), were tested in the oxidation of furfural with hydrogen peroxide. Even substantial changes in acidity and porosity of the catalysts result in minor variations of selectivity towards the desired products. Application of the synthesized zeolite-based materials in the oxidation of furfural with hydrogen peroxide leads to formation of 2(5H)-furanone (yield up to 28.5\%) and succinic acid (up to 19.5\%) as the main C4 reaction products. The kinetic model developed previously to treat the results for oxidation of furfural over sulfated zirconia was able to describe the data also for micro-mesoporous aluminosilicates.

\section{Graphical Abstract}

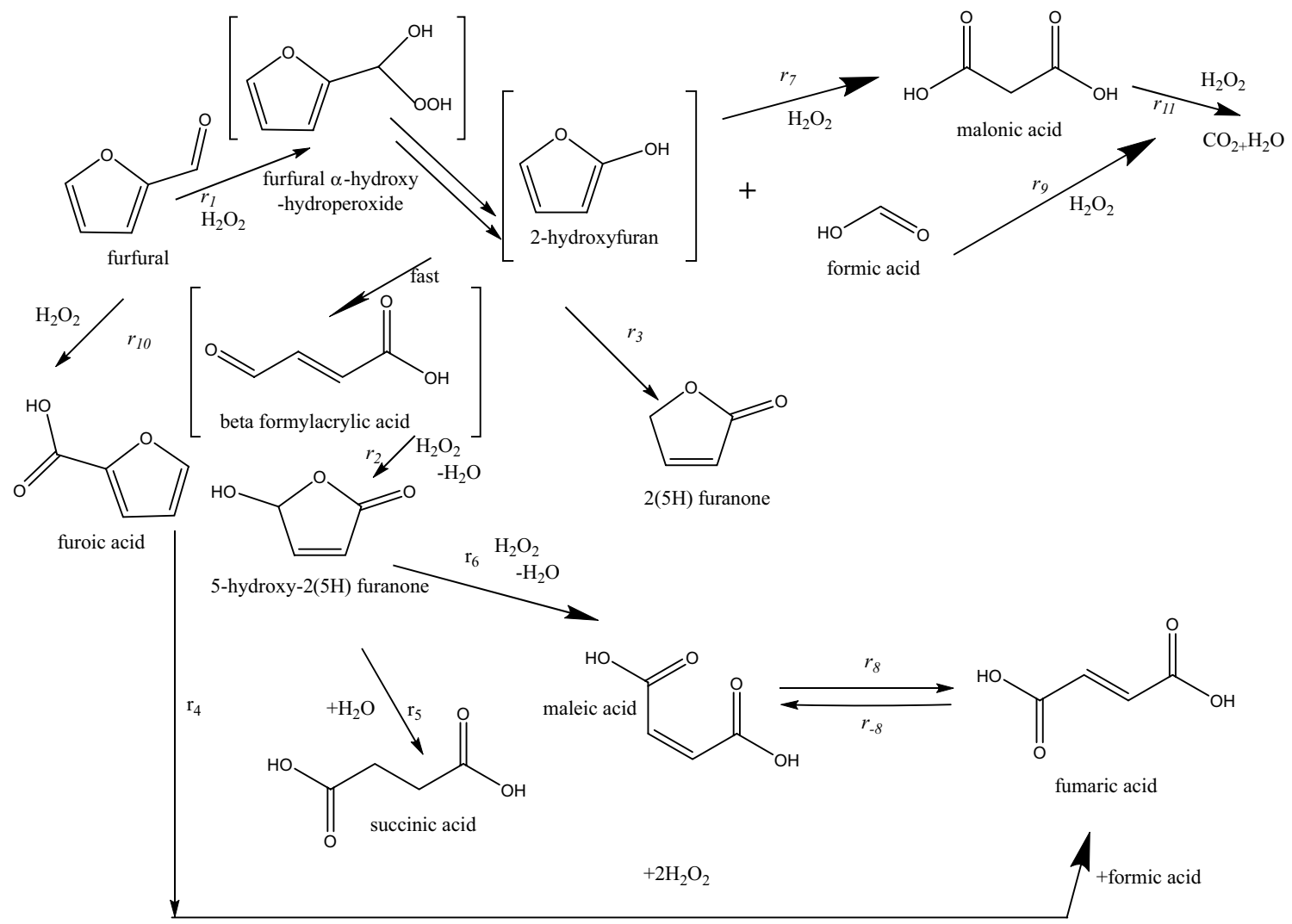

Extended author information available on the last page of the article 
Keywords Furfural oxidation $\cdot$ Zeolite $\cdot$ Micro-mesoporous aluminosilicate $\cdot$ Acid sites

\section{Introduction}

Nowadays processing of renewable resources, especially lignocellulosic biomass, seems to be the most attractive and promising option for the production of chemical compounds in an environmentally friendly and $\mathrm{CO}_{2}$-neutral way [1]. Furfural obtained from lignocellulose is not only a platform molecule for the production of fuels (e.g. tetrahydrofuran), but also a precursor for further synthesis being a universal tool for the preparation of new compounds integrated in the biorefinery concept [2]. One of the promising directions of furfural transformation consists in its oxidation resulting in various organic acids (succinic, maleic, etc.), which are important in the production of drugs, insecticides, resins, plasticizers, etc. [3].

Oxidation of furfural with hydrogen peroxide as a green oxidant has been investigated over Amberlyst-15 [4, 5], sulfonic resins [6], Smopex-101 (poly (ethylene-graft-polystyrene) with sulfonic groups) [7], sulphated zirconia [8], zeolites [4], etc. Moreover, it has been found that the application of betaine hydrochloride as a catalyst leads to the selective formation of maleic and fumaric acid (total yield ' $90 \%$ ) [9]. Bimetallic $\mathrm{CuMoO}_{4}$ has been demonstrated to be selective in the oxidation of furfural to $2(5 \mathrm{H})$-furanone and maleic acid due to the synergetic action of $\mathrm{Cu}$ and Mo species facilitating activation of the carbonyl group of the initial reagent [10]. Acidic (modified with $\mathrm{SO}_{3} \mathrm{H}$ groups) metal-free graphene oxide has been discovered to catalyze effectively oxidation of furfural into succinic acid (yield up to 88\%) [11]. Ultrasonic oxidation of furfural over $\beta$-cyclodextrin- $\mathrm{SO}_{3} \mathrm{H}$ carbon catalyst also results in the selective formation of succinic acid (ca. 81\%) [12]. Furfural has been also upgraded to succinic acid (up to $93 \%$ yield) using polybenzoxazinebased $\mathrm{SO}_{3} \mathrm{H}$-carbocatalysts with nitrogen functionalities [13]. Another valuable product $2(5 \mathrm{H})$-furanone used as an intermediate to produce various value-added products such as fuels, solvents, aroma chemicals, etc. [14, 15] has been obtained (yield up to 52\%) through the oxidation of furfural with hydrogen peroxide using homogeneous acid catalysts [16].

Amberlyst-15 [4] as well as Smopex-101 [7] were discovered to be the most selective towards succinic acid (up to $80 \%$ ) while zeolites demonstrated much lower selectivity (17\%) [4] which was ascribed to spatial limitations of their micropores (in particular, ZSM-5) for the bulk reagents. Therefore, a separate task upon application zeolite catalysts for processing renewable raw materials consists in the creation of hierarchically porous structures, in particular, generation of mesoporosity allowing to accelerate diffusion of the reagents inside the zeolite crystal, as well as to increase the number of accessible active sites $[17,18]$ in this way affecting selectivity [17].

Therefore, the aim of the current paper was to evaluate catalytic activity of ZSM- 5 based micro-mesoporous materials as well as conventional ZSM-5 and Beta zeolites and mesoporous silica in the oxidation of furfural with hydrogen peroxide as a green oxidant in mild conditions.

\section{Experimental}

\subsection{Catalysts Preparation}

For the preparation of 1MMAS (micro-mesoporous aluminosilicate), the low-temperature dual template method using a micellar (25\% CTACl (Aldrich) aqueous solution) and molecular (tetrapropylammonium hydroxide (TPAOH, $40 \%$ aqueous solution, SACHEM, Inc.) templates was applied. A sol-precursor of ZSM-5 zeolite $(\mathrm{Si} / \mathrm{Al}=50$ in the initial reaction mixture) was mixed with $\mathrm{CTACl}$ solution $(\mathrm{CTACl} /$ $(\mathrm{Si}+\mathrm{Al})=0.1)$ followed by stirring for $60 \mathrm{~min}$ and hydrothermal treatment (HTT) at $100{ }^{\circ} \mathrm{C}$ for 2 days (Table 1). The composition of the dual template reaction mixture ( $\mathrm{RM}, \mathrm{pH}$ 12.9) was the following: $1.0 \mathrm{SiO}_{2}: 0.01 \mathrm{Al}_{2} \mathrm{O}_{3}: 0.36 \mathrm{TPAOH}$ : $0.102 \mathrm{CTACl}: 16.27 \mathrm{H}_{2} \mathrm{O}$. The detailed experimental procedure was published earlier in Ref. [19].

In order to synthesize 2MMAS, the pH of a sol-precursor of ZSM-5 zeolite ( $\mathrm{Si} / \mathrm{Al}=50$ ) was adjusted to 11 (from 12.9) using $1.6 \mathrm{M} \mathrm{HCl}$ solution. The resulting dual template mixture $\left[\mathrm{TPAOH} /(\mathrm{Si}+\mathrm{Al})=0.35, \mathrm{H}_{2} \mathrm{O} /(\mathrm{Si}+\mathrm{Al})=35\right]$ was subjected to HTT at $100{ }^{\circ} \mathrm{C}$ for 3 days (Table 1) [19].

3 MMAS was prepared in the presence of a dualfunctional template $N$-hexadecyl- $N^{\prime}$-hexyl- $N, N, N^{\prime}, N^{\prime}$ tetramethyl-1,6-diammoniumhexane dibromide $\left[\mathrm{C}_{16} \mathrm{H}_{33}-\mathrm{N}^{+}\left(\mathrm{CH}_{3}\right)_{2}-\mathrm{C}_{6} \mathrm{H}_{12}-\mathrm{N}^{+}\left(\mathrm{CH}_{3}\right)_{2}-\mathrm{C}_{6} \mathrm{H}_{13}\right]\left(\mathrm{Br}^{-}\right)_{2}$ $\left(\mathrm{C}_{16-6-6} \mathrm{Br}_{2}\right)$ according to the approach described in [20-22]. Such bifunctional template of the Gemini type contains hydrophilic fragments in the space of which the formation of the zeolite structure takes place, and the hydrophobic tails $\mathrm{C}_{16}-\mathrm{C}_{18}$ limiting the crystal growth in one or several directions.

The reaction mixture $(\mathrm{Si} / \mathrm{Al}=50)$ had the following composition: $1.0 \mathrm{SiO}_{2}: 0.01 \mathrm{Al}_{2} \mathrm{O}_{3}: 0.6 \mathrm{NaOH}: 0.1 \mathrm{C}_{16-6-6} \mathrm{Br}_{2}$ : $0.18 \mathrm{H}_{2} \mathrm{SO}_{4}: 40 \mathrm{H}_{2} \mathrm{O}$. TEOS was used as a silicon source, aluminum sulfate octadecahydrate (Sigma-Aldrich, 98\%) - as an aluminum source. A molecular template (TPAOH/ $\mathrm{C}_{16-6-6} \mathrm{Br}_{2}=6.5 \cdot 10^{-3}$, note a low amount of TPAOH) was also applied as an additive. The resulting RM was subjected to HTT at $130{ }^{\circ} \mathrm{C}$ for 6 days in a rotating autoclave (60 rpm) (Table 1). 
Table 1 Parameters of hydrothermal treatment and porosity (from $\mathrm{N}_{2}$ ad(de) sorption at $77 \mathrm{~K}$ ) of the prepared catalysts

\begin{tabular}{llllllll}
\hline Sample & $\begin{array}{l}\text { Hydrothermal } \\
\text { treatment }(\mathrm{HTT})\end{array}$ & $\begin{array}{l}V_{\text {micro }} \bullet 10^{-2} \\
\left(\mathrm{~cm}^{3} / \mathrm{g}\right)\end{array}$ & $V_{\text {meso }}\left(\mathrm{cm}^{3} / \mathrm{g}\right)$ & $D_{\text {meso }}(\mathrm{nm})$ & $S_{\text {meso }}\left(\mathrm{m}^{2} / \mathrm{g}\right)$ & $S_{\text {BET }}\left(\mathrm{m}^{2} / \mathrm{g}\right)$ \\
\cline { 2 - 5 } & $T\left({ }^{\circ} \mathrm{C}\right)$ & $\tau^{\mathrm{a}}$ (days) & & & & & \\
\hline 1MMAS & 100 & 2 & - & 0.57 & 2.3 & 1240 & 1245 \\
2MMAS & 100 & 3 & 0.3 & $0.60 ; 0.30$ & $2.7 ; 16.0$ & 950 & 995 \\
3MMAS & 130 & 6 & $11.5^{\mathrm{b}}$ & 0.30 & 2.7 & 230 & 515 \\
ZSM-5 & 170 & 2 & 14.0 & 0.02 & - & $5^{\mathrm{c}}$ & 375 \\
Beta & 140 & 7 & 23.0 & 0.06 & - & $33^{\mathrm{c}}$ & 618 \\
AlSi-SBA-15 & 100 & 1 & 5.5 & 1.20 & 9.2 & 400 & 530 \\
\hline
\end{tabular}

$V_{\text {micro }}$ Micropore volume, $V_{\text {meso }}$ Mesopore volume, $D_{\text {meso }}$ Mesopore diameter, $S_{\text {meso }}$ Mesopore specific surface area, $S_{\mathrm{BET}}$ Total specific surface area

${ }^{\mathrm{a}} \tau$ is the HTT duration

${ }^{\mathrm{b}}$ The average micropore diameter for 1MMAS, 2MMAS, 3MMAS and ZSM-5 is $0.55 \mathrm{~nm}$, for AlSiSBA-15 is ca. $0.80 \mathrm{~nm}$, for Beta zeolite is ca. $0.90 \mathrm{~nm}$

${ }^{\mathrm{c}}$ The sum of mesopore and external surface area of ZSM-5 and Beta zeolites
The reference samples $-\mathrm{ZSM}-5(\mathrm{Si} / \mathrm{Al}=50$ in the initial reaction mixture), Beta $(\mathrm{Si} / \mathrm{Al}=35)$ and $\mathrm{AlSi}-\mathrm{SBA}-15$ $(\mathrm{Si} / \mathrm{Al}=50)$ were prepared using the standard procedures described in [23, 24] and [25], respectively.

All the obtained materials were thoroughly washed with distilled water, dried and calcined in air at $550{ }^{\circ} \mathrm{C}$ for $5 \mathrm{~h}\left(2{ }^{\circ} \mathrm{C} / \mathrm{min}\right)$. After calcination 3MMAS, ZSM-5 and Beta were subjected to triple ion-exchange in $1 \mathrm{M}$ $\mathrm{NH}_{4} \mathrm{Cl}$ solution at room temperature for $24 \mathrm{~h}$ with the subsequent conversion of the obtained $\mathrm{NH}_{4}^{+}$-forms into $\mathrm{H}$-forms using a standard experimental procedure (heating at $550{ }^{\circ} \mathrm{C}$ for $5 \mathrm{~h}$, the rate of $2{ }^{\circ} \mathrm{C} / \mathrm{min}$ ).

\subsection{Characterization}

The phase composition of the prepared materials was investigated using X-ray diffractometer D8 ADVANCE (Bruker $\mathrm{AXS}$ ) with $\mathrm{Cu} K_{\alpha}$-radiation. The degree of crystallinity of the partially crystalline samples was estimated by the change in the ratio of the intensities of the characteristic reflexes at $2 \theta=23.0^{\circ} ; 23.8^{\circ} ; 24.2^{\circ}$ compared to highly crystalline ZSM-5 zeolite, for which the degree of crystallinity was considered as unity.

The content of $\mathrm{Si}$ and $\mathrm{Al}$ in the prepared samples was determined by energy dispersive X-ray spectroscopy (FEI Quanta 200 FEG instrument).

The SEM images of the synthesized catalysts were obtained using the field emission SEM FEI Quanta 200 FEG. The images were taken using an accelerating voltage of $15-20 \mathrm{kV}$ and a beam current of $0.65 \mathrm{nA}$. Before imaging the samples were coated with a platinum film of $15 \mathrm{~nm}$ thickness, using a sputtering method. The TEM images were obtained using the field emission TEM JEM-2100F (JEOL) with an accelerating voltage of $200 \mathrm{kV}$. The sample was dispersed in ethanol in an ultrasonic bath for $5 \mathrm{~min}$ followed by the application of the suspension to a copper grid coated with a carbon film.

Nitrogen ad(de)sorption was measured by a volumetric method (77 K, up to $1 \mathrm{~atm}$ ) using an analyzer of porous materials Sorptomatic 1990 (Thermo Electron Corp.). Before the measurements the samples were evacuated $(P \leq 0.7 \mathrm{~Pa})$ at $350{ }^{\circ} \mathrm{C}$ for $5 \mathrm{~h}$. The specific surface area $S_{\mathrm{BET}}$ was determined by BET equation [26], an average micropore size was evaluated by the method of SaitoFoley [27]. The mesopore size was calculated from the desorption branches of the isotherms, using the method of Barrett-Joyner-Halenda (BJH) [28]. The micropore and mesopore volumes as well as the mesopore surface area and external surface area for S-shaped isotherms (IV type) were determined using the comparative t-plot method [29]. The micropore volume of ZSM-5 and Beta zeolites was calculated by the Dubinin-Radushkevich equation [30].

Acidity of the catalysts was investigated by the standard method of temperature-programmed desorption of ammonia (ammonia TPD) [31]. The samples were activated for $30 \mathrm{~min}$ in the helium flow at $550{ }^{\circ} \mathrm{C}$ (heating rate was $15^{\circ} \mathrm{C} / \mathrm{min}$ ), cooled to $100{ }^{\circ} \mathrm{C}$ and saturated with $\mathrm{NH}_{3}$ for $20 \mathrm{~min}$; physically bound ammonia was desorbed by purging with helium at $100{ }^{\circ} \mathrm{C}$. The residual $\mathrm{NH}_{3}$ was desorbed by the temperature-programmed heating in the temperature range of $100-700{ }^{\circ} \mathrm{C}\left(15^{\circ} \mathrm{C} / \mathrm{min}\right)$. The positions of the ammonia desorption maxima were determined using chromatograph LHM-80 (thermal conductivity detector) and registered as a TPDA curve. The total amount of desorbed $\mathrm{NH}_{3}$ was calculated by the titrating with $1 \cdot 10^{-3} \mathrm{M} \mathrm{HCl}$ solution using an automatic titrating burette. The peak positions of ammonia thermal desorption were determined by the deconvolution of TPDA curves using the Gaussian distribution. According to the 
position of the temperature maximum of $\mathrm{NH}_{3}$ desorption, the acid sites can be attributed to weak ( $T_{\max }$ of desorption $\left.<300{ }^{\circ} \mathrm{C}\right)$, medium strength $\left(T_{\max }\right.$ at $\left.300-400{ }^{\circ} \mathrm{C}\right)$ and strong $\left(T_{\max }>400{ }^{\circ} \mathrm{C}\right)[19]$.

Pyridine ad(de)sorption with an IR-spectral control being a common method for the investigation of zeolites and mesoporous molecular sieves (MMS), was applied for the determination of the nature, strength and concentration of acid sites [21]. The thin plates of the studied materials $\left(8-12 \mathrm{mg} / \mathrm{cm}^{2}\right.$, without a binder) were placed in a cuvette with $\mathrm{NaCl}$ windows and evacuated $(P=1.4 \mathrm{~Pa})$ at $400{ }^{\circ} \mathrm{C}$ for $1 \mathrm{~h}$. Afterwards pyridine was adsorbed at $150{ }^{\circ} \mathrm{C}$ for $15 \mathrm{~min}$, and desorbed at $150-400{ }^{\circ} \mathrm{C}$ (step $50{ }^{\circ} \mathrm{C}$, holding time $30 \mathrm{~min}$ ). The concentration of Lewis (L-sites) and Brønsted (B-sites) acid sites was estimated from the integral intensity of the absorption bands at $1454 \mathrm{~cm}^{-1}$ and $1545 \mathrm{~cm}^{-1}$ respectively using the integral molar extinction coefficients for the indicated bands: $\varepsilon(L)=2.22 \mathrm{~cm} / \mu \mathrm{mol}$ and $\varepsilon(B)=1.67 \mathrm{~cm} / \mu \mathrm{mol}$ [32].

Taking into account inaccessibility of the micropores of ZSM-5 zeolite for 2,6-di-tert-butylpyridine (DTBPy, kinetic diameter is $0.8 \mathrm{~nm}$ [33]), the method of DTBPy ad(de)sorption with an IR-spectral control was used to determine the nature, strength and concentration of acid sites accessible for bulk molecules. The experimental procedure is similar to the one described for pyridine. The concentration of B-sites was estimated by the integral intensity of the absorption band at $1530 \mathrm{~cm}^{-1}$ using the integral molar extinction coefficient $\varepsilon(B)=1.67 \mathrm{~cm} /$ $\mu \mathrm{mol}[34]$.

\subsection{Catalytic Tests}

Oxidation of furfural with hydrogen peroxide was performed according to the previously published procedure for Smopex-101 and sulphated zirconia [7, 8]. Furfural (Sigma Aldrich, $\geq 98 \mathrm{wt} \%$ ) was used as received without further treatment. The reaction products $(2(5 \mathrm{H})$-furanone, formic, succinic, furoic, maleic, fumaric, malonic and malic acids) were purchased from various suppliers and applied as standards.

The reaction was performed in a three-neck isothermal glass reactor equipped with a reflux condenser, a mechanical agitator and a heating jacket. In a typical kinetic experiment, the initial concentration of furfural was $0.5 \mathrm{~mol} / \mathrm{l}$, the catalyst weight $-0.1 \mathrm{~g}$, the stirring speed $-500 \mathrm{rpm}$. Deionized water was used as a solvent $(\mathrm{V}=70 \mathrm{ml})$, the reaction temperature was $75^{\circ} \mathrm{C}$. After the reaction mixture reached the desired temperature, hydrogen peroxide was injected into the reactor $\left(\mathrm{H}_{2} \mathrm{O}_{2}\right.$ /furfural ratio $=4$, excess was taken to counterbalance potential $\mathrm{H}_{2} \mathrm{O}_{2}$ decomposition). The reaction was carried out under constant helium flow $(15 \mathrm{ml} / \mathrm{min})$.
The samples were taken from the reactor at different time intervals, filtered with a $0.45 \mu \mathrm{m}$ syringe filter and analyzed by HPLC using HPLC Agilent 1100 series equipped with an RI detector and an Aminex HPX-87H column $(300 \times 7.8 \mathrm{~mm})$. Sulphuric acid $(5 \mathrm{mmol} / \mathrm{l})$ was used as a mobile phase.

\section{Results and Discussion}

\subsection{Catalysts Characterization}

Low-temperature dual template synthesis results in the formation of an X-ray amorphous material (1MMAS) characterized by mesostructure (the interplanar distance corresponding to the first reflex $d_{0}=3.5 \mathrm{~nm}$ ) with a relatively low ordering degree (Fig. 1a, c). According to our previous paper [35] the synthesized sample contains secondary building units of ZSM-5 as was demonstrated by FTIR spectroscopy. In particular, an absorption band at ca. $550 \mathrm{~cm}^{-1}$ corresponded to an asymmetric stretching vibration of (alumino) siloxane bond in five-membered ring of $\mathrm{Si}(\mathrm{Al}) \mathrm{O}_{4 / 2}$ tetrahedra [36]. The morphology of 1MMAS is mainly uniform being presented by amorphous spherical particles of ca. $2 \mu \mathrm{m}$ in size (Fig. 2a) similar to alumino-silica MMS MCM-41.

2MMAS being a material with a low degree of zeolitization $(<0.10$, Fig. 1c) possesses an ordered mesostructure (Fig. 1a). This sample contains, along with the amorphous material, also zeolite crystallites with the size of ca. $\sim 0.5 \mu \mathrm{m}$ (Fig. 2b). According to our previous paper [19] similar partially zeolitized materials exhibit both the wormhole mesopores and straight mesopores typical for MCM- 41 . The presence of wormhole mesoporosity was ascribed to the imperfection of mesostructure.

3MMAS generated in the reaction mixture with the dualfunctional template $\mathrm{C}_{16-6-6} \mathrm{Br}$ in combination with the additive of TPAOH, is a crystalline material (Fig. 1c) consisting of ZSM-5 nanoparticles agglomerates. A small-angle reflex in the XRD pattern of 3MMAS (Fig. 1b) testifies a high uniformity of zeolite nanoparticles in size and shape. The indicated zeolite type sample consists of flake-like particles (the packs of ZSM-5 zeolite, Fig. 2c) separated by the nanoparticles ("pillars") as was previously demonstrated in [35]. The presence of pillars between the ZSM-5 layers leads to the preservation of the low-ordered lamellar mesostructure during calcination (Fig. 1b). ZSM-5 consists of typical large (ca. $1.5 \mu \mathrm{m}$ ) spherical particles (Fig. 2d).

Sorption characteristics of the prepared samples obtained from the nitrogen ad(de)sorption isotherms (Fig. S1) are presented in Table 1. 1MMAS contains quite uniform mesopores (diameter $2.3 \mathrm{~nm}$ ). The decrease of the $\mathrm{pH}$ of the zeolite-forming reaction mixture (from 12.9 to 11) results in the formation (2MMAS) of obviously interparticle 

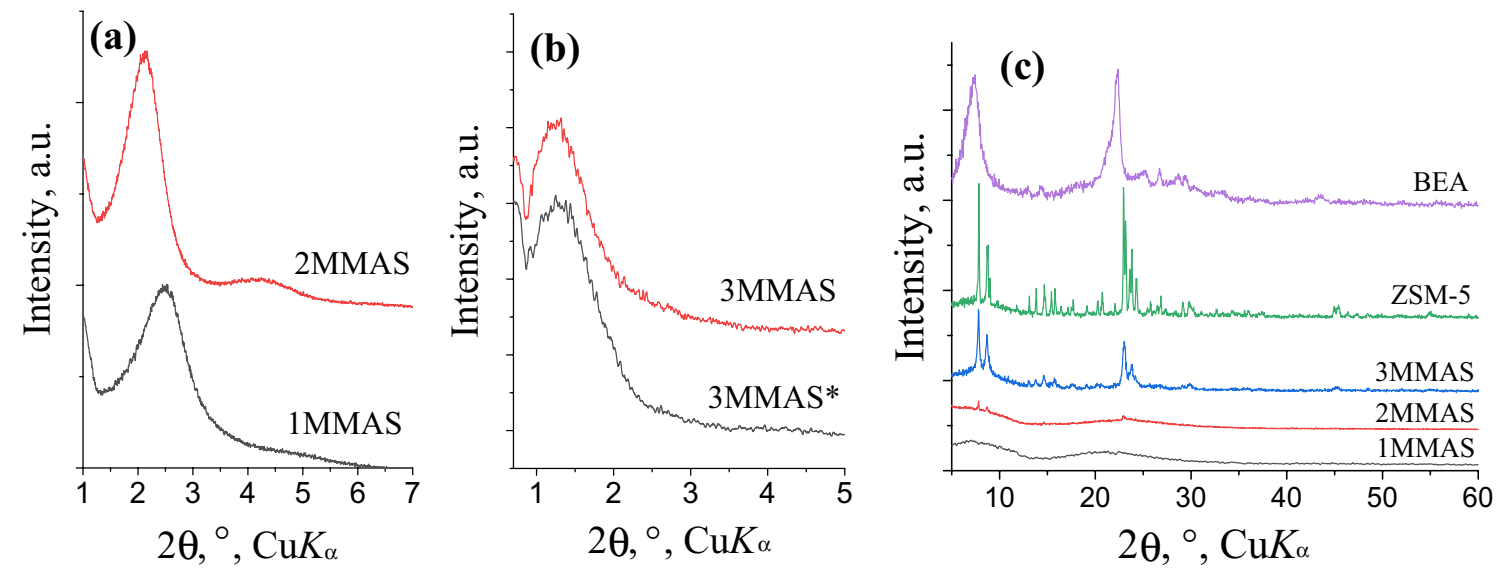

Fig. 1 XRD patterns of the calcined zeolite materials in low- $(\mathbf{a}, \mathbf{b})$ and high-angle (c) regions (an as-synthesized sample is marked with asterisk)
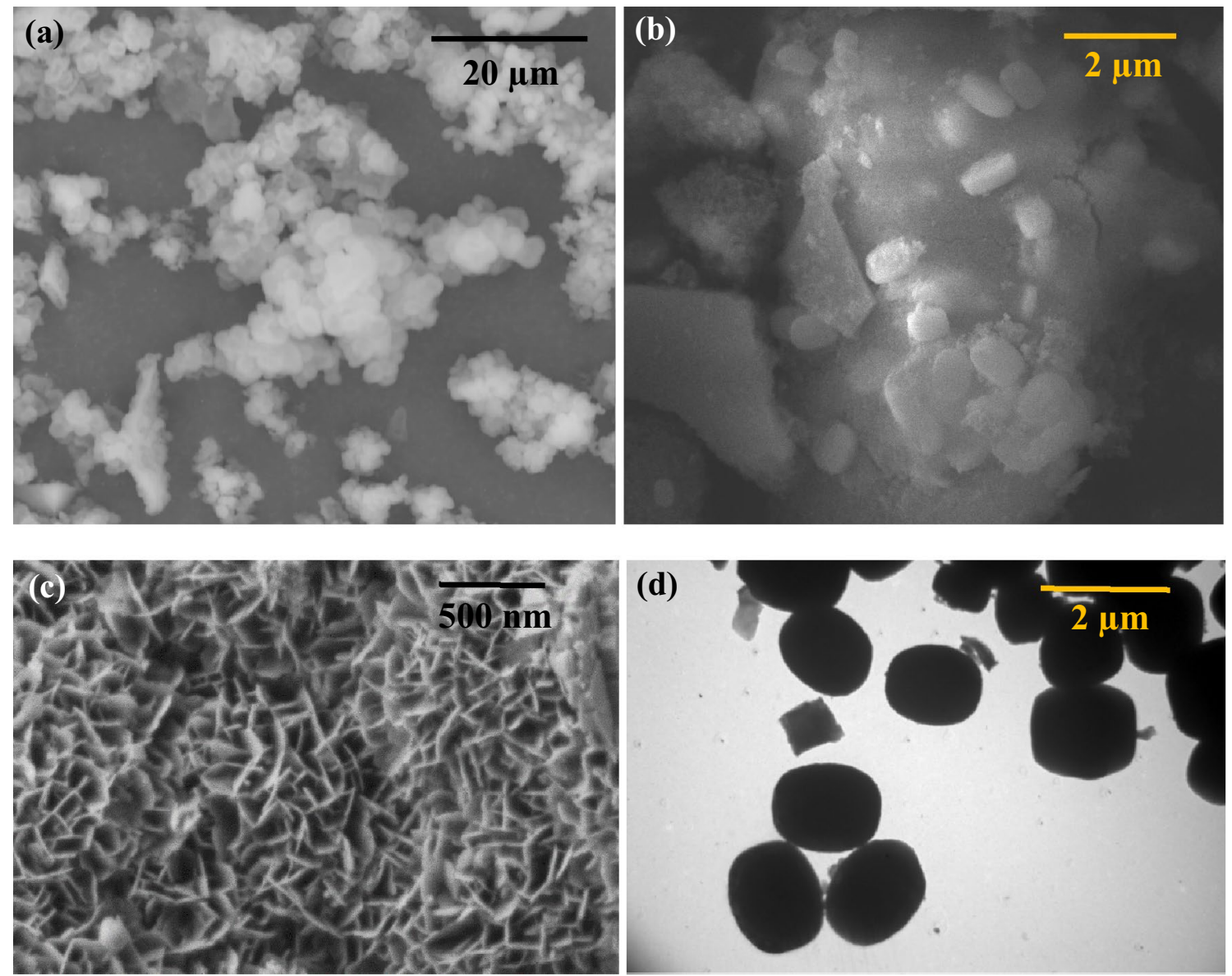

Fig. 2 SEM (a-c) and TEM (d) images of 1MMAS (a), 2MMAS (b), 3MMAS (c) and ZSM-5 (d)

mesopores $\left(V_{\text {meso }}=0.30 \mathrm{~cm}^{3} / \mathrm{g}, D_{\text {meso }}=16 \mathrm{~nm}\right)$ along with the typical ones of MCM-41 $(2.7 \mathrm{~nm})$. In addition, the formation of zeolite crystallites leads to a decrease in mesopore volume and specific surface area, as well as the appearance of micropores typical of ZSM-5 $\left(D_{\text {micro }}=0.55 \mathrm{~nm}\right.$, Table 1$)$. The porosity of 3MMAS is presented by micropores inherent to ZSM-5 zeolite $\left(V_{\text {micro }}=0.11 \mathrm{~cm}^{3} / \mathrm{g}\right)$ and homogeneous in size interparticle mesopores $\left(V_{\text {meso }}=0.30 \mathrm{~cm}^{3} / \mathrm{g}\right.$, 
Table 2 Acidity of the prepared catalysts from ammonia TPD

\begin{tabular}{lllc}
\hline Sample & Si/Al & \multicolumn{2}{l}{ Acidity by TPDA } \\
\cline { 3 - 4 } & & $\left.T_{\max }{ }^{\mathrm{a}}{ }^{\circ} \mathrm{C}\right)$ & $C(\mu \mathrm{mol} / \mathrm{g})$ \\
\hline 1MMAS & 33 & 210 & 60 \\
& & 320 & 154 \\
2MMAS & 44 & 205 & 47 \\
& & 320 & 90 \\
3MMAS & 42 & 200 & 213 \\
& & 440 & 217 \\
ZSM-5 & 30 & 210 & 170 \\
& & 440 & 136 \\
AlSi-SBA-15 & 23 & 215 & 34 \\
& & 300 & 61 \\
Beta & 20 & 210 & 73 \\
& & 345 & 213 \\
\hline
\end{tabular}

${ }^{\mathrm{a}} T_{\max }$, temperature of the maximum of $\mathrm{NH}_{3}$ desorption

$D_{\text {meso }}=2.7 \mathrm{~nm}, S_{\text {meso }}=230 \mathrm{~m}^{2} / \mathrm{g}$ ). The indicated mesopores correspond to the voids between zeolite nanolayers agglomerated during the synthesis and subsequent calcination (Fig. 2c). Beta zeolite contains mainly micropores (Table 1) similar to ZSM-5. AlSi-SBA-15 is characterized by the presence of a large volume $\left(1.2 \mathrm{~cm}^{3} / \mathrm{g}\right)$ of uniform mesopores $(\mathrm{D}=9.2 \mathrm{~nm})$.

According to the results of ammonia TPD (Fig. S2, Table 2), the X-ray amorphous material 1MMAS possessing secondary building units of ZSM-5 zeolite contains mainly medium strength acid sites in the concentration of ca. $150 \mu \mathrm{mol} / \mathrm{g}$ (maximum of $\mathrm{NH}_{3}$ desorption at $320^{\circ} \mathrm{C}$ ). According to ad(de)sorption of pyridine with the IR-spectral control, 1MMAS is characterized by a significant concentration of medium strength Brønsted $(74 \mu \mathrm{mol} / \mathrm{g}$, pyridine is completely desorbed at $350{ }^{\circ} \mathrm{C}$ ) and Lewis acid sites $(150 \mu \mathrm{mol} / \mathrm{g}$, the temperature of complete desorption is above $400{ }^{\circ} \mathrm{C}$ ), which also indicates the presence of zeolite precursors in its mesostructure. It is worth noting that the concentration of Lewis acid sites in the above sample is almost twice higher than the concentration of Brønsted acid sites (Fig. 3).

The partially zeolitized 2MMAS sample contains medium strength acid sites (the temperature of ammonia desorption is $320^{\circ} \mathrm{C}$ ) with the total concentration of $137 \mu \mathrm{mol} / \mathrm{g}$. The total concentration of acid sites in the prepared X-ray amorphous and partially crystalline materials (ca. $200-140 \mu \mathrm{mol} / \mathrm{g}$ ) was measured to be much lower than the expected values ( 400-250 $\mu \mathrm{mol} / \mathrm{g})$, calculated considering the aluminium content in the samples (Table 2). The above difference was explained by the inaccessibility of a certain $\mathrm{Al}$ fraction for bases or its octahedral coordination resulting in the absence of acidity [19]. In addition, the concentration and strength of Brønsted acid sites is naturally lower in comparison with
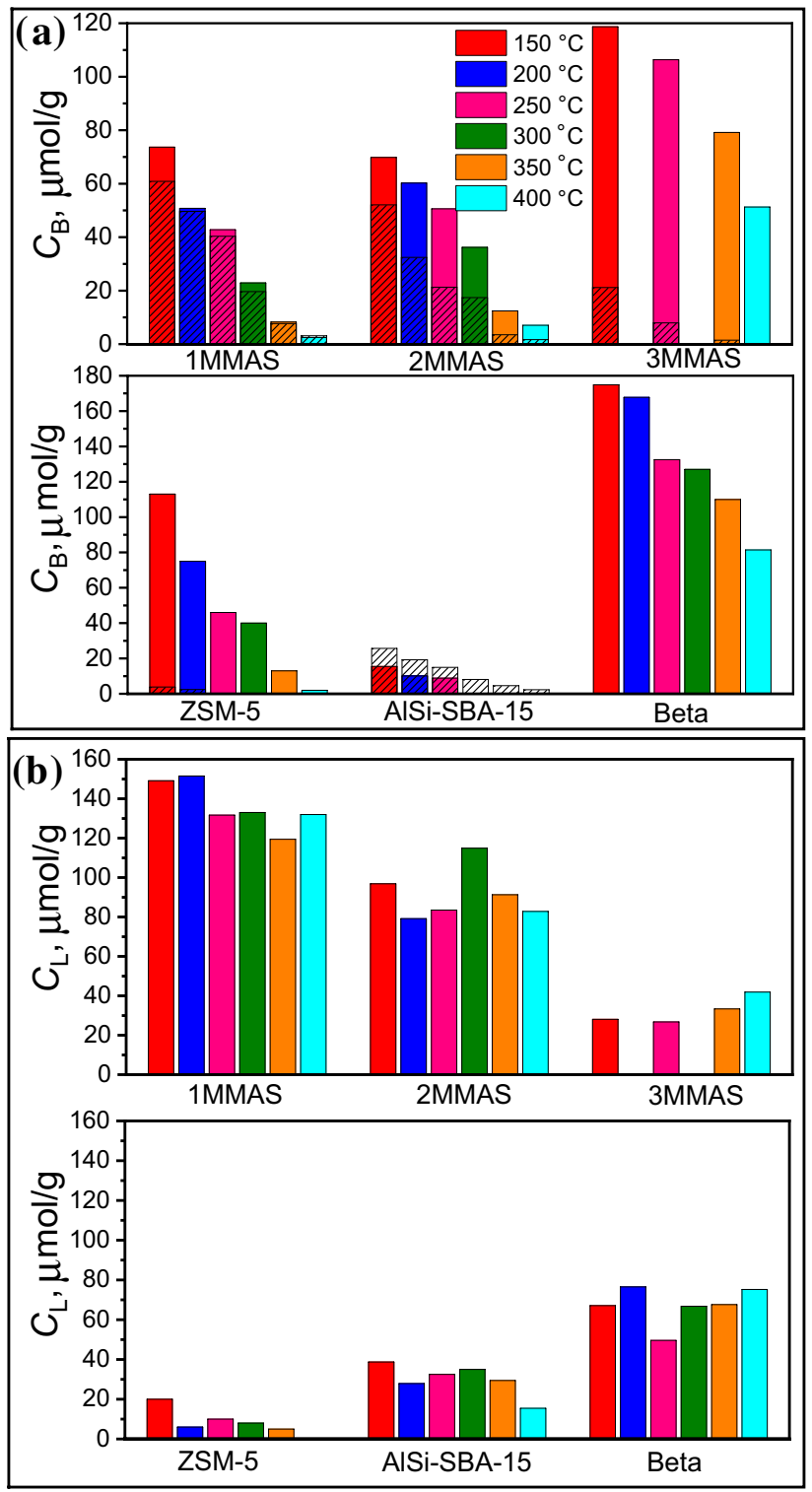

Fig. 3 Histograms of the dependence of concentration of pyridine interacting with Brønsted (a) and Lewis (b) acid sites on the desorption temperature (150-450 ${ }^{\circ} \mathrm{C}$ ) for 1MMAS-3MMAS, ZSM-5, AlSiSBA-15, Beta (shaded columns for 2,6-di-tert-butylpyridine)

ZSM- 5 zeolite $(113 \mu \mathrm{mol} / \mathrm{g}$, the temperature of pyridine desorption is $400{ }^{\circ} \mathrm{C}$, Fig. 3).

3MMAS $(\mathrm{Si} / \mathrm{Al}=42)$, being a highly crystalline material, contains strong acid sites (Table 2), similar to ZSM-5 zeolite $(\mathrm{Si} / \mathrm{Al}=30)$. Compared to other samples, this material exhibits stronger Brønsted acid sites (the temperature of complete pyridine desorption is $450{ }^{\circ} \mathrm{C}$ ) in higher concentration, and a higher ratio of Brønsted to Lewis acidity. Beta zeolite is characterized by an increased concentration of Brønsted acid sites (Fig. 3). The amorphous nature of AlSi-SBA-15 reflects a low acid sites concentration in this material (Table 2, Fig. 3). 
According to 2,6-di-tert-butylpyridine (DTBPy) adsorption (Fig. 3), most of the Brønsted acid sites in 1MMAS and 2MMAS are accessible for bulk molecules (accessibility index is ca. 0.7-0.8) being located either on the mesopore surface for X-ray amorphous material or on the external surface of zeolite crystallites for partially crystalline sample [35]. A high micropore content in 3MMAS is responsible for a low accessibility index of Brønsted acid sites (ca. 0.2).

\subsection{Catalytic Activity}

As was shown previously [8] furfural can be oxidized without a catalyst yielding formic acid, $2(5 \mathrm{H})$-furanone, succinic acid and other products in minor quantities. Furfural oxidation has been considered as an autocatalytic reaction [8] because formic acid generated from unstable 2-hydroxyfuran is capable to catalyze the process homogeneously. The application of the catalyst (e.g. sulfated zirconia) resulted in an increase of the reaction rate yielding together with the main products $(2(5 \mathrm{H})$-furanone, formic and succinic acids) also maleic acid and 5-hydroxy-2(5H)-furanone. The corresponding reaction scheme is presented in Fig. 4, showing the formed products.

Prepared micro-mesoporous aluminosilicates, ZSM-5 and Beta zeolites, as well as mesoporous silica AlSi-SBA-15 for comparison were tested in the oxidation of furfural with hydrogen peroxide. As can be seen from the obtained corresponding kinetic curves (Fig. 5), the reaction products are $2(5 \mathrm{H})$-furanone, formic, succinic, maleic, malic and other organic acids presented in smaller amounts as well as 5-hydroxy-2 $(5 \mathrm{H})$-furanone reported previously to be formed over sulfated zirconia [8].

As it is known [37] oxidation of furfural results in furfural- $\alpha$-hydroxyhydroperoxide via the Bayer-Villiger reaction followed by the transformation of unstable 2-formyloxyfuran hydrolyzing to 2-hydroxyfuran (giving various organic acids) and formic acid. The results of furfural oxidation with hydrogen peroxide are summarized in Table 3.

As can be seen from Fig. 5 a transition from 1 to 3MMAS allows higher furfural oxidation rates as well as an increase in the amount of succinic acid and $2(5 \mathrm{H})$-furanone. Application of Beta zeolite affords a faster furfural transformation, however, a lower yield of succinic acid and $2(5 \mathrm{H})$-furanone while the yield of maleic acid is turned out to be higher than with other samples (Table 3 ).

Selectivity dependence towards some reaction products, namely succinic acid, $2(5 \mathrm{H})$-furanone, maleic acid and 5-hydroxy-2 $(5 \mathrm{H})$-furanone on the conversion of furfural is presented in Fig. 6. All the curves except the one for 5-hydroxy-2(5H)-furanone (Fig. 5d) demonstrate a general trend of an increase of selectivity with conversion connected

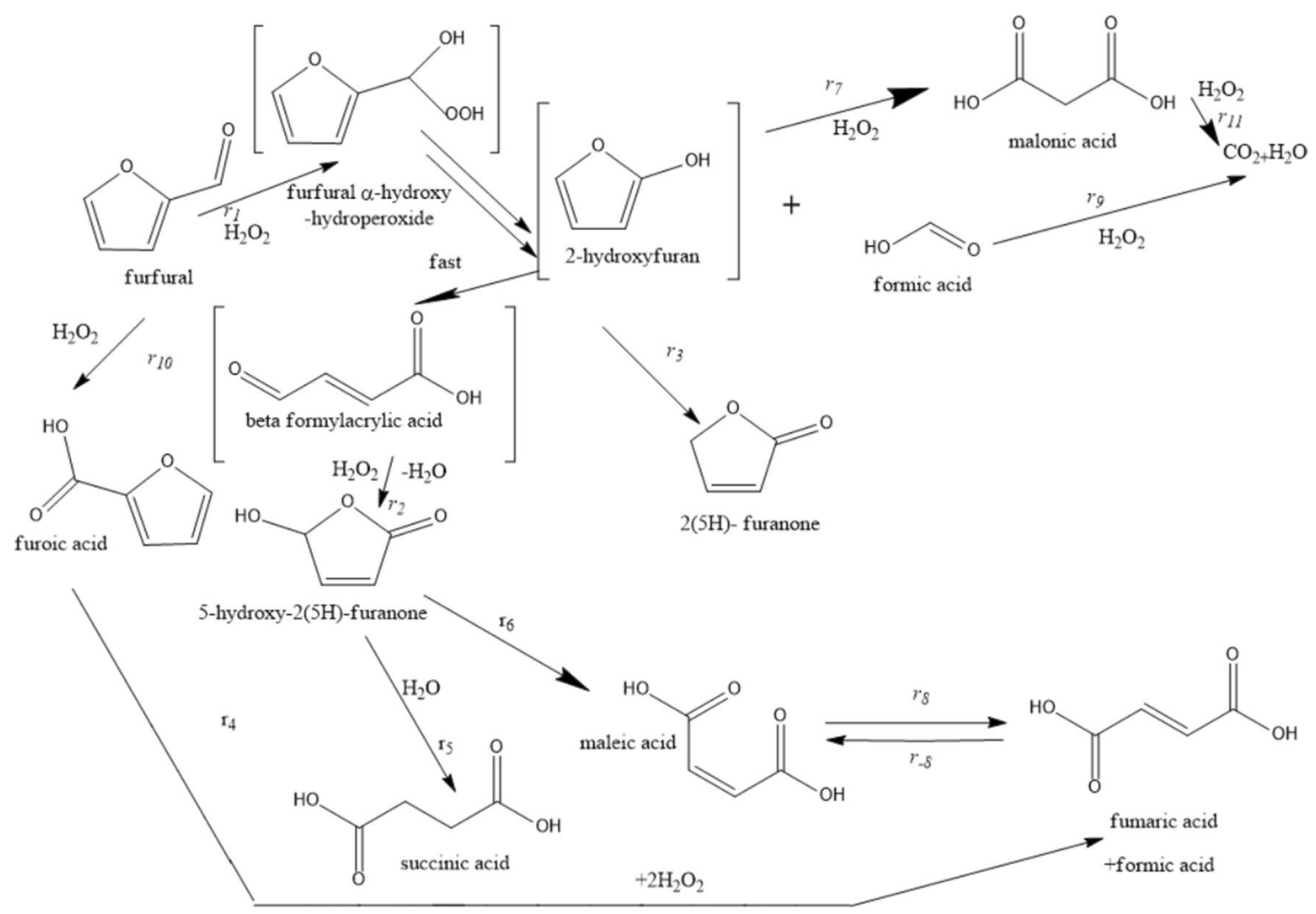

Fig. 4 Reaction scheme of furfural oxidation. Modified from [8] based on the experimental results and kinetic modelling of this work 

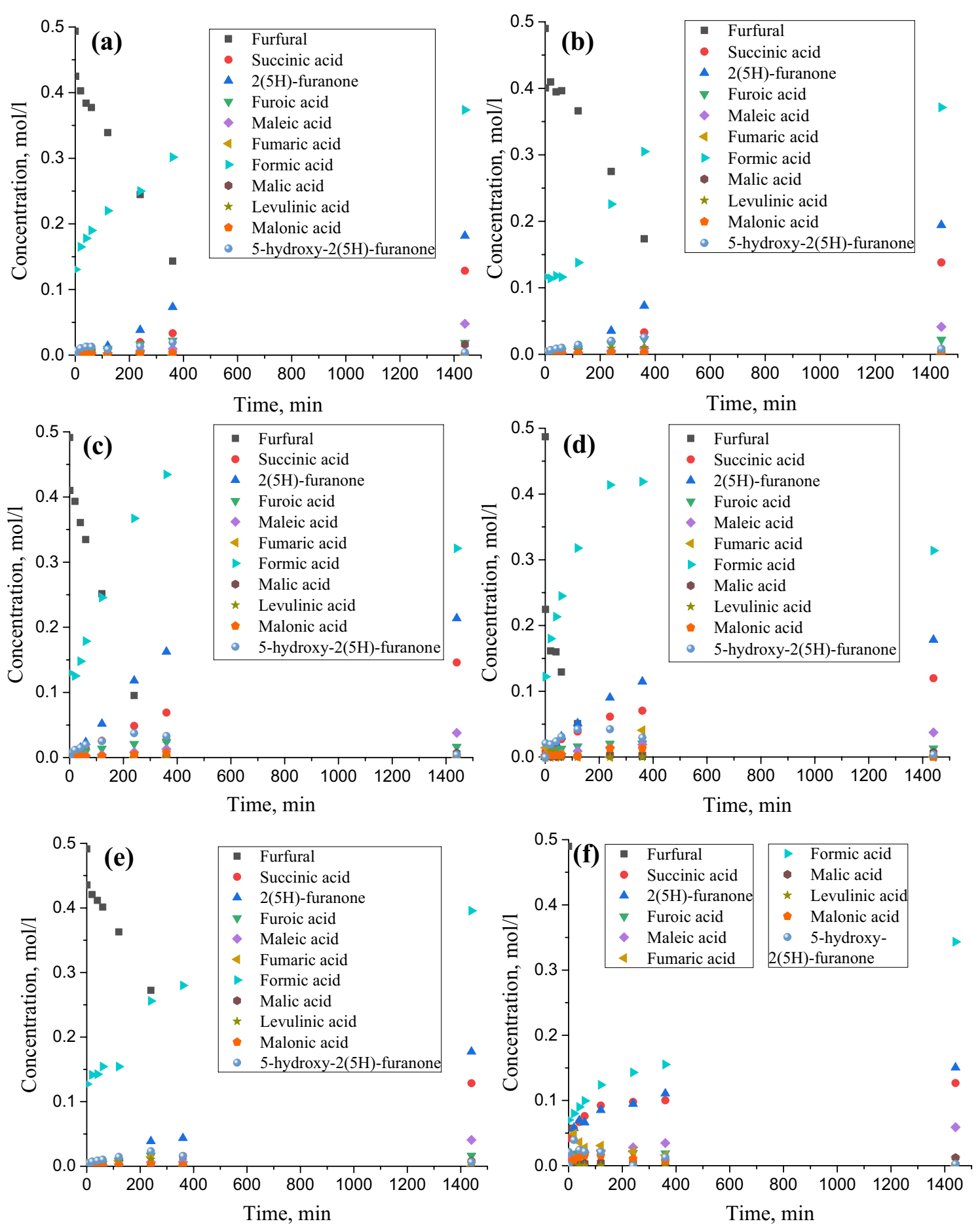

Fig. 5 Concentration curves of furfural oxidation with hydrogen peroxide over the prepared zeolite-based catalysts: $\mathbf{a}-1 \mathrm{MMAS}, \mathbf{b}-2 \mathrm{MMAS}$, c - 3MMAS, d - ZSM-5, e - AlSi-SBA-15, f - Beta

with the parallel routes of their formation from 2-hydroxyfuran [8]. A decrease of selectivity towards 5-hydroxy$2(5 \mathrm{H})$-furanone with conversion (Fig. 6d) is obviously associated with its involvement in consecutive reactions, namely yielding succinic and maleic acids [8].
Influence of acidity of all prepared catalysts on the catalytic performance was also analyzed (Fig. 7). In particular, the yields of $2(5 \mathrm{H})$-furanone, succinic acid and maleic acid only slightly increased with a rise of the ratio of Brønsted and Lewis acid sites determined by the pyridine 
Table 3 Catalytic results for the prepared materials in oxidation of furfural with hydrogen peroxide

\begin{tabular}{lrlllll}
\hline Catalyst & $\begin{array}{l}\text { Reaction rate, } \\
\text { mmol/min } g_{\text {cat }}\end{array}$ & $\begin{array}{l}\text { Selectivity } \\
\text { to } 2(5 \mathrm{H})- \\
\text { furanone }\end{array}$ & $\begin{array}{l}\text { Selectivity to } \\
\text { succinic acid }\end{array}$ & $\begin{array}{l}\text { Selectivity } \\
\text { to maleic } \\
\text { acid }\end{array}$ & $\begin{array}{l}\text { Selectivity } \\
\text { to malic } \\
\text { acid }\end{array}$ & $\begin{array}{l}\text { Selectivity to } \\
\text { malonic acid }\end{array}$ \\
\hline 1MMAS & 3.5 & 23.6 & 16.7 & 6.2 & 2.1 & 0.7 \\
2MMAS & 4.1 & 24.7 & 17.6 & 5.3 & 1.0 & 0.01 \\
3MMAS & 4.3 & 28.5 & 19.5 & 5.1 & 0.9 & - \\
ZSM-5 & 14.5 & 26.5 & 17.8 & 5.5 & 1.0 & 0.1 \\
AlSi-SBA-15 & 3.1 & 22.6 & 16.4 & 5.2 & 1.0 & 0.8 \\
Beta & 20.5 & 21.3 & 17.9 & 8.4 & 1.7 & 0.3 \\
\hline
\end{tabular}

Conditions: $\mathrm{m}_{\text {cat }}-0.1 \mathrm{~g}$, time $-24 \mathrm{~h}, \mathrm{~T}-75^{\circ} \mathrm{C}, \mathrm{C}_{\text {furfural }}-0.5 \mathrm{~mol} / \mathrm{l}$
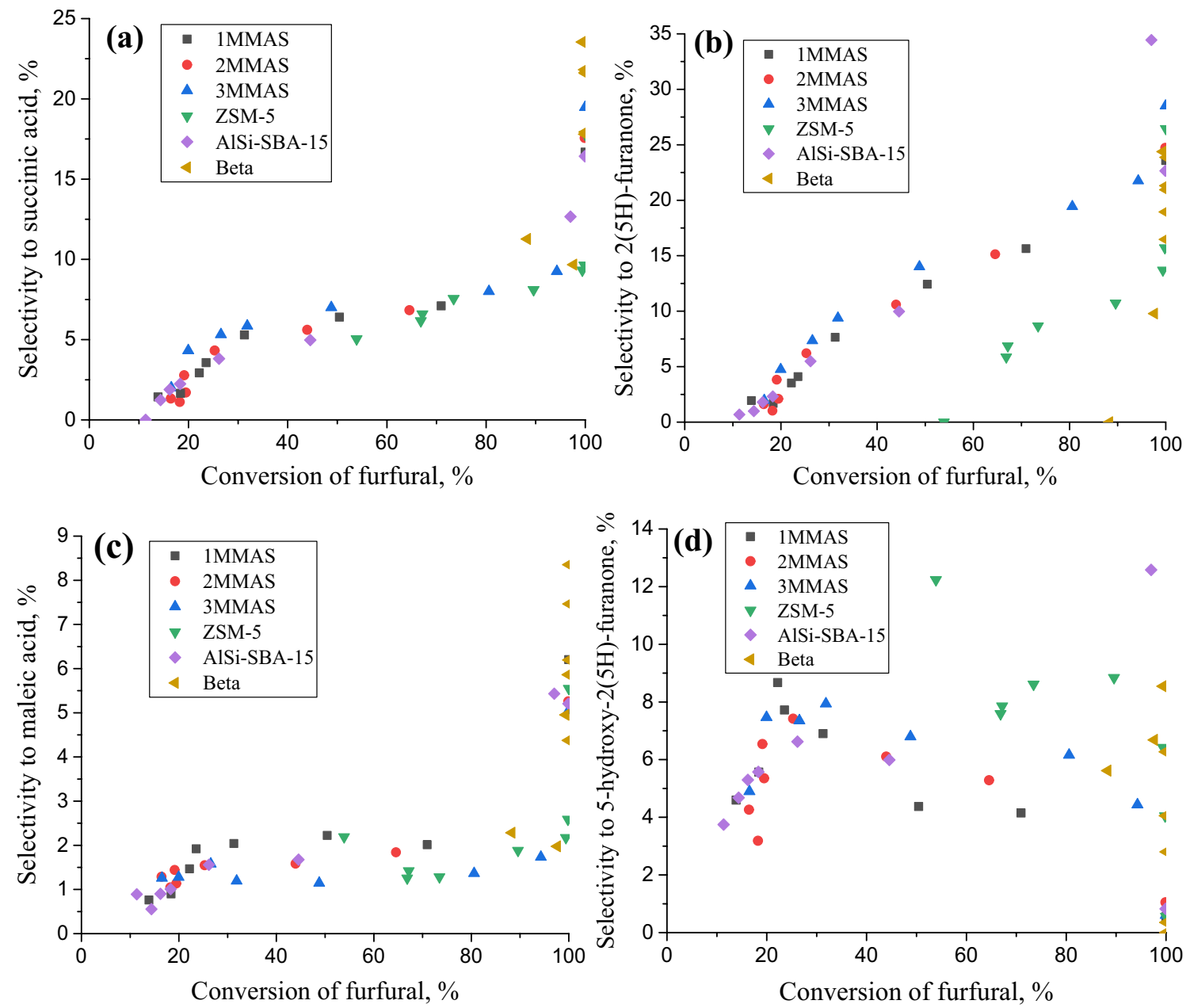

Fig. 6 Selectivity towards succinic acid (a), 2(5H)-furanone (b), maleic acid (c) and 5-hydroxy-2(5H)-furanone (d) as a function of furfural conversion over the investigated catalysts

ad(de)sorption (Fig. 7a). The correlation of the parameter $S_{\text {meso }} / S_{\mathrm{BET}} * C_{\mathrm{B}}$ reflecting the influence of acidity $\left(C_{\mathrm{B}}\right)$ and the fraction of the accessible acid sites $\left(S_{\text {meso }} / S_{\mathrm{BET}}\right)[38]$ with the yield of the targeted products is presented in Fig. $7 \mathrm{~b}$. The yield of $2(5 \mathrm{H})$-furanone slightly increased with an increase of the indicated parameter while the yields of succinic and maleic acid remained almost unchanged. Considering the above results, it can be concluded that even significant differences both in acidity and porosity, in particular upon transition from amorphous or low crystalline zeolite-based materials to highly crystalline traditional zeolites, result only 

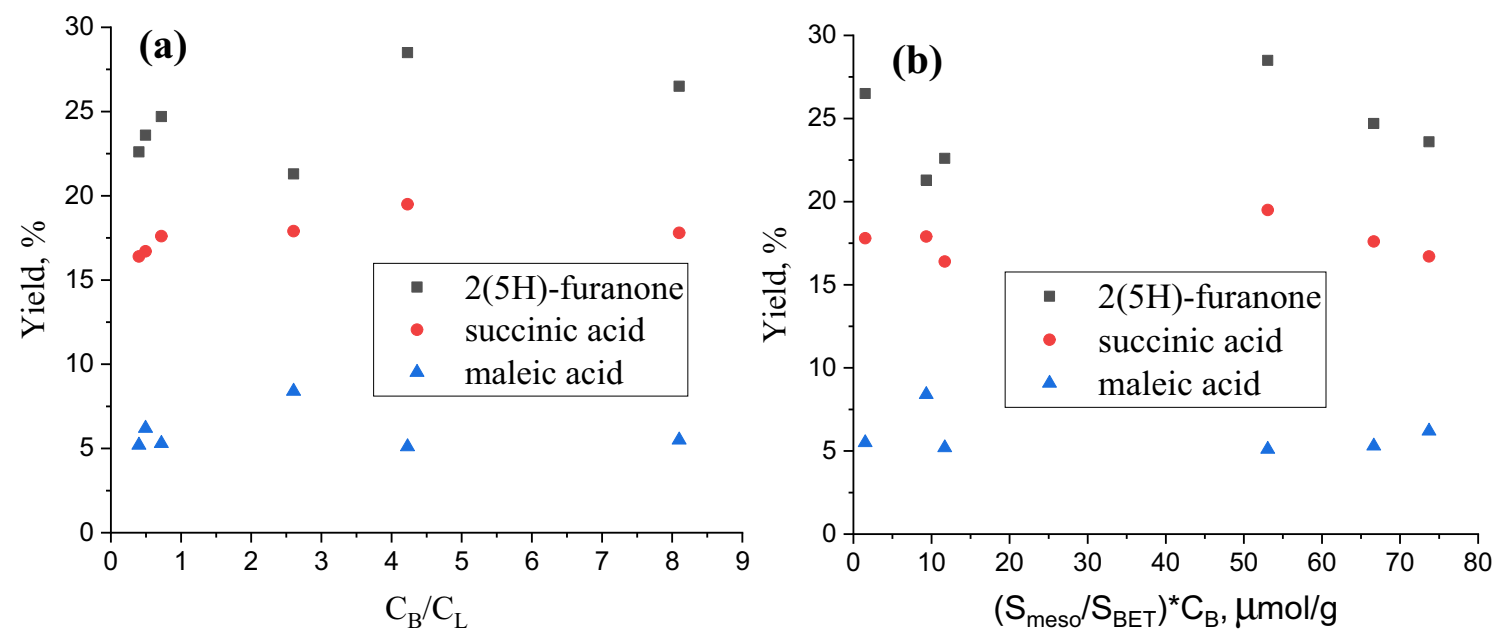

Fig. 7 The yields of 2(5H)-furanone, succinic and maleic acids as a function of $\mathbf{a}$ The ratio of Brønsted and Lewis acid sites and $\mathbf{b}$ Brønsted acid sites concentration on the mesopore surface

in minor changes of selectivity towards the desired reaction products.

Separate catalytic experiments aimed at catalyst reusability elucidation showed a stable furfural conversion (ca. $98-100 \%$ of the initial value) and selectivity to the desired products. Prior to reusage, the samples were subjected to an activation procedure by heat treatment in air $\left(450^{\circ} \mathrm{C}, 2 \mathrm{~h}\right)$ typical for zeolitic materials.

Overall analysis of concentration dependencies and selectivity points out on strong similarities between oxidation of furfural over sulfated zirconia [8] and the current data with zeolite based catalysts. To illustrate that the same reaction network can be used, kinetic analysis of the data generated in this work was performed using previously reported kinetic model [8]. For the sake of avoiding repetitions, only few kinetic equations will be presented here for illustration purposes. For instance, the generation equations for the main reactants and products are.
Details of the parameter estimation were presented in the previous contribution [8].

Taking into account a large number of parameters and a rather limited data set for each material, it was expected that the estimated values for at least several rate constants will have high errors. Therefore, kinetic modelling was aimed at demonstrating applicability of the model to explain the data rather than to determine in a precise and statistically reliable way values of all parameters. Subsequently results of the calculations for only 2MMAS and 3MMAS are presented in Fig. 8 clearly illustrating applicability of the kinetic model to treat the data, as the model was capable to capture changes in the concentrations for the reacting compounds.

The coefficient of determination $\mathrm{R}^{2}$ defined with respect to the variance of all experimental points relative to the mean value of all observations was in the range 96-97\% also confirming an adequate fit. The values of kinetic parameters with the corresponding errors are given in Tables 4 and 5

$\frac{1}{\rho_{B}} \frac{d C_{\text {furfural }}}{d t}=-r_{1}-r_{10} ; \frac{1}{\rho_{B}} \frac{d C_{\text {formic_acid }}}{d t}=r_{1}+r_{4}+r_{7}-r_{9} ; \frac{1}{\rho_{B}} \frac{d C_{\text {succinic_acid }}}{d t}=-r_{5} ; \frac{1}{\rho_{B}} \frac{d C_{2(5 H) f u r a n o n e}}{d t}=r_{3}$

where $\rho_{B}$ is the catalyst bulk density (the catalyst mass divided by the liquid volume), $r$ is rate of a particular step in Fig. $4, C_{i}$ - is the concentration of compound $i$ and $t$ is time. The reaction rates for all reactions in Fig. 4, where hydrogen peroxide is involved, were considered to be of first order in hydrogen peroxide. In addition, all reactions are of first order towards the organic compounds. Overall, in the model, experimentally measured concentrations of 11 organic compounds were compared with the calculations using the numerical data fitting software ModEst [39]. confirming that the rate constants for formation of minor compounds (e.g. fumaric or malonic) are poorly identified as the errors for the corresponding constants (e.g. $\mathrm{k}_{+8}, \mathrm{k}_{-8}$ ) are large. Similar to the parameter estimation procedure for sulphated zirconia formation of maleic acid from $2(5 \mathrm{H})$ furanone could be disregarded even if such formation from the chemical viewpoint is possible. On the other hand, concentration of $2(5 \mathrm{H})$-furanone within the studied reaction time was approaching a constant value (more clearly seen for 3MMAS), thus its consecutive transformations are apparently slow. 


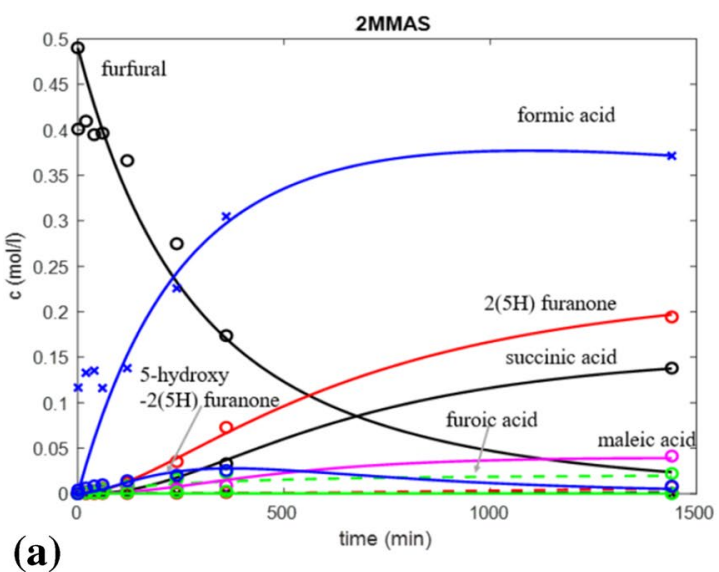

(a)

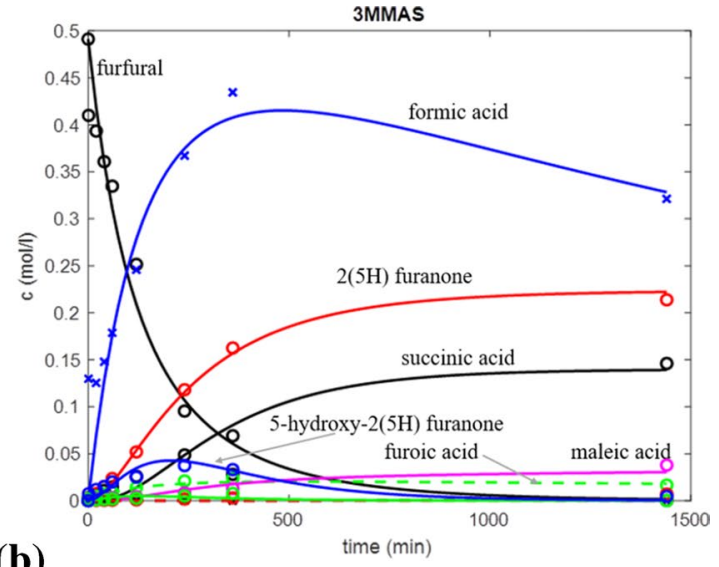

(b)

Fig. 8 Comparison between experimental (symbols) and calculated (lines) concentrations of reactants and products for a $2 \mathrm{MMAS}$ and b 3MMAS catalyst

Table 4 Results of parameter estimation for 2MMAS catalyst

\begin{tabular}{|c|c|c|c|c|c|c|}
\hline $\begin{array}{l}\text { Parameter } \\
\text { Units }\end{array}$ & $\begin{array}{l}k_{+1} \rho_{B} \\
\mathrm{~L}^{2} / \mathrm{mol}^{2} / \mathrm{min}\end{array}$ & $\begin{array}{l}k_{+2} \rho_{B} \\
\mathrm{~L}^{2} / \mathrm{mol}^{2} / \mathrm{min}\end{array}$ & $\begin{array}{l}k_{+3} \rho_{B} \\
\mathrm{~L} / \mathrm{mol} / \mathrm{min}\end{array}$ & $\begin{array}{l}k_{+4} \rho_{B} \\
\mathrm{~L}^{2} / \mathrm{mol}^{2} / \mathrm{min}\end{array}$ & $\begin{array}{l}k_{+5} \rho_{B} \\
\mathrm{~L} / \mathrm{mol} / \mathrm{min}\end{array}$ & $\begin{array}{l}k_{+6} \rho_{B} \\
\mathrm{~L}^{2} / \mathrm{mol}^{2} / \mathrm{min}\end{array}$ \\
\hline Value & 1.45 & 0.99 & 1.1 & $<10^{-3}$ & 4.3 & 1.41 \\
\hline Error, \% & 11.1 & 55.6 & 46.5 & $>100$ & 73.3 & $>100$ \\
\hline $\begin{array}{l}\text { Parameter } \\
\text { Units }\end{array}$ & $\begin{array}{l}k_{+7} \rho_{B} \\
\mathrm{~L}^{2} / \mathrm{mol}^{2} / \mathrm{min}\end{array}$ & $\begin{array}{l}k_{+8} \rho_{B} \\
\mathrm{~L} / \mathrm{mol} / \mathrm{min}\end{array}$ & $\begin{array}{l}k_{-8} \rho_{B} \\
\mathrm{~L} / \mathrm{mol} / \mathrm{min}\end{array}$ & $\begin{array}{l}k_{+9} \rho_{B} \\
\mathrm{~L}^{2} / \mathrm{mol}^{2} / \mathrm{min}\end{array}$ & $\begin{array}{l}k_{+10} \rho_{B} \\
\mathrm{~L}^{2} / \mathrm{mol}^{2} / \mathrm{min}\end{array}$ & $\begin{array}{l}k_{+11} \rho_{B} \\
\mathrm{~L}^{2} / \mathrm{mol}^{2} / \min \end{array}$ \\
\hline Value & 0.163 & 5.53 & 211 & 0.18 & 0.06 & 106 \\
\hline Error, \% & $>100$ & $>100$ & $>100$ & 91.8 & $>100$ & $>100$ \\
\hline
\end{tabular}

Table 5 Results of parameter estimation for 3MMAS catalyst

\begin{tabular}{|c|c|c|c|c|c|c|}
\hline $\begin{array}{l}\text { Parameter } \\
\text { Units }\end{array}$ & $\begin{array}{l}k_{+1} \rho_{B} \\
\mathrm{~L}^{2} / \mathrm{mol}^{2} / \mathrm{min}\end{array}$ & $\begin{array}{l}k_{+2} \rho_{B} \\
\mathrm{~L}^{2} / \mathrm{mol}^{2} / \mathrm{min}\end{array}$ & $\begin{array}{l}k_{+3} \rho_{B} \\
\mathrm{~L} / \mathrm{mol} / \mathrm{min}\end{array}$ & $\begin{array}{l}k_{+4} \rho_{B} \\
\mathrm{~L}^{2} / \mathrm{mol}^{2} / \mathrm{min}\end{array}$ & $\begin{array}{l}k_{+5} \rho_{B} \\
\mathrm{~L} / \mathrm{mol} / \mathrm{min}\end{array}$ & $\begin{array}{l}k_{+6} \rho_{B} \\
\mathrm{~L}^{2} / \mathrm{mol}^{2} / \mathrm{min}\end{array}$ \\
\hline Value & 3.3 & 2.1 & 3.07 & 0.3 & 5.05 & 0.83 \\
\hline Error, $\%$ & 7.0 & 35.6 & 31.4 & $>100$ & 34.7 & $>100$ \\
\hline Parameter & $k_{+7} \rho_{B}$ & $k_{+8} \rho_{B}$ & $k_{-8} \rho_{B}$ & $k_{+9} \rho_{B}$ & $k_{+10} \rho_{B}$ & $k_{+11} \rho_{B}$ \\
\hline Units & $\mathrm{L}^{2} / \mathrm{mol}^{2} / \mathrm{min}$ & $\mathrm{L} / \mathrm{mol} / \mathrm{min}$ & $\mathrm{L} / \mathrm{mol} / \mathrm{min}$ & $\mathrm{L}^{2} / \mathrm{mol}^{2} / \mathrm{min}$ & $\mathrm{L}^{2} / \mathrm{mol}^{2} / \min$ & $\mathrm{L}^{2} / \mathrm{mol}^{2} / \mathrm{min}$ \\
\hline Value & 1.0 & 2.7 & 976 & 0.39 & 0.183 & 27.5 \\
\hline Error, \% & 81.4 & $>100$ & $>100$ & 56.5 & 71.1 & $>100$ \\
\hline
\end{tabular}

\section{Conclusions}

Oxidation of furfural with hydrogen peroxide over micromesoporous aluminosilicates based on ZSM-5 zeolite, obtained by a dual template method and in the presence of a dual-functional template, as well as ZSM-5, Beta zeolites and mesoporous molecular sieve AlSi-SBA-15 applied as the reference materials, was investigated. Minor changes of selectivity towards the desired products were found even if acidity and porosity of the catalyst were substantially different. Within the MFI zeolite structure application of the hierarchical zeolite with a developed mesopore surface area resulting in the enhanced accessibility of Brønsted acid sites for bulk molecules allows to reach a slightly higher yield of the desired products (succinic acid and 2(5H)-furanone - up to $19.5 \%$ and $28.5 \%$, respectively) compared to traditional ZSM-5 zeolite and MMS AlSi-SBA-15. 
The kinetic model advanced previously to treat the experimental data for oxidation of furfural over sulphated zirconia was extended to describe the data also for micro-mesoporous aluminosilicates.

Supplementary Information The online version contains supplementary material available at https://doi.org/10.1007/s10562-021-03899-9.

Acknowledgements The authors gratefully acknowledge the financial support of the National Research Foundation of Ukraine to the project "New effective zeolite catalysts for environmentally friendly processes of the conversion of renewable raw materials into valuable organic compounds" (project number 2020.02/0335). N.S. also acknowledges the support of the Verkhovna Rada of Ukraine to a personal scholarship for young scientists-doctors of sciences for 2021.

Funding Open access funding provided by Abo Akademi University (ABO).

\section{Declarations}

Conflict of interest The authors declare no conflict of interest.

Open Access This article is licensed under a Creative Commons Attribution 4.0 International License, which permits use, sharing, adaptation, distribution and reproduction in any medium or format, as long as you give appropriate credit to the original author(s) and the source, provide a link to the Creative Commons licence, and indicate if changes were made. The images or other third party material in this article are included in the article's Creative Commons licence, unless indicated otherwise in a credit line to the material. If material is not included in the article's Creative Commons licence and your intended use is not permitted by statutory regulation or exceeds the permitted use, you will need to obtain permission directly from the copyright holder. To view a copy of this licence, visit http://creativecommons.org/licenses/by/4.0/.

\section{References}

1. Zhang H, Yang W, Roslan II, Jaenicke S, Chuah GK (2019) J Catal $375: 56$

2. Rubio-Caballero JM, Saravanamurugan S, Maireles-Torres P, Riisager A (2014) Catal Today 234:233

3. Murzin DY, Saleem F, Warnå J, Salmi T (2020) Chem Eng J 382:122811

4. Choudhary H, Nishimura S, Ebitani K (2012) Chem Lett 41:409

5. Choudhary H, Nishimura S, Ebitani K (2013) Appl Catal A Gen 458:55

6. Kingkaew W, Kaewwiset T, Thubsuang U, Siripattana C, Nuithitikul K (2020) Key Eng Mater 856:182

7. Saleem F, Mueller P, Eränen K, Wärnå J, Murzin DYu, Salmi T (2017) J Chem Tech Biotech 92:2206

8. Murzin DY, Bertrand E, Tolvanen P, Devyatkov S, Rahkila J, Eränen K, Wärnå J, Salmi T (2020) Ind Eng Chem Res 59:13516

9. Araji N, Madjinza DD, Chatel G, Moores A, Jérôme F, Vigier KDO (2017) Green Chem 19:98
10. Yu X, Liu H, Wang Q, Jia W, Wang H, Li W, Zheng J, Sun Y, Tang X, Zeng X, Xu F, Lin L (2021) ACS Sust Chem Eng 9:13176

11. Zhu W, Tao F, Chen S, Li M, Yang Y, Lv G (2018) ACS Sust Chem Eng 7:296

12. Maneechakr P, Karnjanakom S (2017) Energy Convers Manag $154: 299$

13. Thubsuang U, Chotirut S, Nuithitikul K, Payaka A, Manmuanpom N, Chaisuwan T, Wongkasemjit S (2020) J Colloid Interf Sci 565:96

14. Lima CGS, Monteiro JL, De Melo LT, Paixao MW, Correa AG (2018) Chemsuschem 11:25

15. Effenberger I, Hoffmann T, Jonczyk R, Schwab W (2019) Sci Rep 9:10943

16. Bhat NS, Kumar R, Jana A, Mal SS, Dutta S (2021). Biomass Conv Bioref. https://doi.org/10.1007/s13399-021-01297-0

17. Kerstens D, Smeyers B, Van Waeyenberg J, Zhang Q, Yu J, Sels BF (2020) Adv Mater 32:2004690

18. Khan W, Jia X, Wu Z, Choi J, Yip AC (2019) Catalysts 9:127

19. Barakov R, Shcherban N, Yaremov P, Gryn S, Solomakha V, Bezverkhyy I, Kasian N, Ilyin V (2016) J Mater Sci 51:4002

20. Na K, Choi M, Park W, Sakamoto Y, Terasaki O, Ryoo R (2010) J Am Chem Soc 132:4169

21. Kim K, Ryoo R, Jang HD, Choi M (2012) J Catal 288:115

22. Barakov R, Shcherban N, Yaremov P, Bezverkhyy I, Baranchikov A, Trachevskii V, Tsyrina V, Ilyin V (2017) Micropor Mesopor Mater 237:90

23. Laugel G, Nitsch X, Ocampo F, Louis B (2011) Appl Catal A Gen 402:139

24. Barakov R, Shcherban N, Yaremov P, Bezverkhyy I, Tsyrina V, Opanasenko M (2020) Appl Catal A Gen 594:117380

25. Wu S, Han Y, Zou YC, Song JW, Zhao L, Di Y, Liu SZ, Xiao FS (2004) Chem Mater 16:486

26. Brunauer S, Emmett PH, Teller E (1938) J Am Chem Soc 60:309

27. Saito A, Foley HC (1991) AIChE J 37:429

28. Barrett EP, Joyner LG, Halenda PP (1951) J Amer Chem Soc 73:373

29. Lippens BC, de Boer JH (1965) J Catal 4:319

30. Dubinin MM (1965) Russ J Phys Chem 39:697

31. Hu S, Shan J, Zhang Q, Wang Y, Liu Y, Gong Y, Wu Z, Dou T (2012) Appl Catal A Gen 445:215

32. Emeis CA (1993) J Catal 141:347

33. Góra-Marek K, Tarach K, Choi M (2014) J Phys Chem C 118:12266

34. Jo C, Ryoo R, Žilková N, Vitvarová D, Čejka J (2013) Catal Sci Technol 3:2119

35. Shcherban ND, Barakov RY, Mäki-Arvela P, Sergiienko SA, Bezverkhyy I, Eränen K, Murzin DY (2018) Appl Catal A Gen 560:236

36. Kirschhock CEA, Ravishankar R, Verspeurt F, Grobet PJ, Jacobs PA, Martens JA (1999) J Phys Chem B 103:4965

37. Badovskaya LA, Poskonin VV (2018) Russ J Gen Chem 88:1568

38. Barakov R, Shcherban N, Petrov O, Lang J, Shamzhy M, Opanasenko M, Čejka J (2021) Inorg Chem Front (submitted)

39. H. Haario, ModEst, Software for parameter estimation (Helsinki, 2001).

Publisher's Note Springer Nature remains neutral with regard to jurisdictional claims in published maps and institutional affiliations. 


\section{Authors and Affiliations}

Nataliya D. Shcherban ${ }^{1} \cdot$ Roman Yu. Barakov $^{1} \cdot$ Sergii A. Sergiienko $^{2} \cdot$ Kari Eränen $^{3} \cdot$ Johan Wärnå $^{3}$.

Dmitry Yu. Murzin ${ }^{3}$

$\triangle$ Dmitry Yu. Murzin

dmurzin@abo.fi

1 L.V. Pisarzhevsky Institute of Physical Chemistry, National Academy of Sciences of Ukraine, 31 pr. Nauky, Kyiv 03028, Ukraine
2 Department of Materials and Ceramics Engineering, University of Aveiro, CICECO-Aveiro Institute of Materials, 3810-193 Aveiro, Portugal

3 Johan Gadolin Process Chemistry Centre, Åbo Akademi University, Biskopsgatan 8, 20500 Abo/Turku, Finland 